\title{
Markers of tumor invasion are major predictive factors for the long-term outcome of corticotroph microadenomas treated by transsphenoidal adenomectomy
}

\author{
S Vallette-Kasic ${ }^{1}$, H Dufour ${ }^{2}$, M Mugnier ${ }^{1}$, J Trouillas ${ }^{4}$, H Valdes-Socin ${ }^{1}$, P Caron ${ }^{5}$, S Morange ${ }^{3}$, N Girard ${ }^{6}$, \\ $\mathrm{F}_{\text {Grisoli }}{ }^{2}$, P Jaquet ${ }^{1}$ and T Brue ${ }^{1}$ \\ Departments of ${ }^{1}$ Endocrinology, ${ }^{2}$ Neurosurgery and ${ }^{3}$ Medical Information, Centre Hospitalier Universitaire (CHU) Timone, Marseille, ${ }^{4}$ Laboratory of \\ Histology-Embryology, INSERM, Faculté de Médecine Laennec, Lyon, ${ }^{5}$ Department of Endocrinology, CHU Rangueuil, Toulouse and ${ }^{6}$ Department of \\ Radiology, CHU Nord, Marseille, France
}

(Correspondence should be addressed to T Brue, Hopital de la Timone, 264 rue St Pierre, 13385 Marseille Cedex 5, France; Email: tbrue@ap-hm.fr)

\begin{abstract}
Objective: To assess the postsurgical outcome of patients with corticotroph microadenomas and to define predictors of the long-term outcome, with special emphasis on markers of tumor extension. Design: Prospective study of 53 corticotroph microadenomas treated by enlarged adenomectomy. Patients followed for at least 2 years were classified into two groups: those in long-term remission and uncured patients (immediate failures and recurrences). Pre-, per- and postoperative parameters were analyzed as predictors of the long-term outcome.

Methods: Baseline hormone assessments were performed preoperatively, 8 days after surgery and every 6-12 months thereafter. Pituitary magnetic resonance imaging (MRI) allowed analysis of possible tumor extension to adjacent structures. Apparent completeness of the surgical removal was determined, and fragments labeled either 'tumor' or 'surrounding pituitary tissue' were submitted to serial sectioning.

Results: Immediate control of hypercortisolism was achieved in $43 / 53$ patients $(81 \%)$. However, later recurrences were observed in five patients $(9 \%)$. Preoperative MRI showed tumor extension into adjacent structures with good specificity $(91 \%)$ for prediction of surgical failure. Evidence of local invasion at surgery was also significantly predictive of the long-term outcome. A corticotroph adenoma was found at histological examination in $96 \%$ of the patients, and $26 \%$ had irregular limits, a feature significantly correlated with a poor outcome. Immediate postoperative plasma cortisol did not allow discrimination between long-term remissions and recurrences.

Conclusion: Surgical failure was best predicted by signs of tumor 'invasiveness' at MRI, confirmed by peroperative examination and histology.
\end{abstract}

European Journal of Endocrinology 143 761-768

\section{Introduction}

Cushing's disease is the first cause of hypercortisolism, but remains a rare affliction. Its incidence in the general population is estimated to be between 0.7 and 2.4 cases/million per year $(1,2)$. Without treatment, hypercortisolism leads to severe complications and is associated with premature mortality. Most pituitary tumors in Cushing's disease are microadenomas. Since the first removal of a corticotroph microadenoma by transsphenoidal surgery by Hardy in 1969 (3), pituitary microsurgery has become the treatment of choice for Cushing's disease $(4,5)$. The immediate success rate ranges from 70 to $85 \%(1,6-12)$. However, the recurrence rate after initially successful surgical treatment increases with the duration of the follow-up, to reach as much as $20 \%$ at $5-6$ years $(1,9$, 12-15).

It is widely accepted that measurement of postoperative cortisol concentrations can be used both to assess the immediate control of hypercortisolism and to provide a partial prediction of the likelihood of recurrence $(9,13,16-18)$. In contrast, several attempts at using dynamic tests in this setting have provided controversial results $(1,12,15-17,19,20)$. The principal aim of our study was thus to determine other prognostic factors that may be linked to either absence of immediate cure or later recurrence of Cushing's disease after transsphenoidal surgery. In addition to the clinical and biological parameters usually monitored in these patients, we more particularly focused our attention on: 1) the evaluation of 
tumor invasion by preoperative magnetic resonance imaging (MRI) by the same neuroradiologist (N G) using three-dimensional sequences; 2) the systematic peroperative evaluation of the efficacy of the surgical removal by the neurosurgeon; 3) the careful histological analysis of the adenomas on serial sections of all removed fragments, in addition to the analysis of the juxtatumoral pituitary tissue. Identification of several possible risk factors might be helpful in improving the final success rate of surgery. In this respect, a surgical strategy characterized by a deliberate attempt at performing a curative removal of the tumor by the same experienced neurosurgeon (F G) was chosen. On the assumption that unsuccessful surgical removals were accounted for by insufficient adenomectomy because of the presence of tumoral cells at the periphery of the adenoma, an enlarged adenomectomy was carried out (21).

From 1989 to 1998, a cohort of 53 consecutive patients presenting with corticotroph microadenomas and treated by enlarged adenomectomy was prospectively studied using this approach and has been followed for a mean duration of $37.9 \pm 22.1$ months (range 24-120 months) after transsphenoidal surgery.

\section{Patients and methods}

\section{Patients}

In each patient, the diagnosis of corticotroph microadenoma was established on the basis of a combination of the usual criteria: clinical findings, baseline and pharmacodynamic hormone evaluations, radiological evidence of a microadenoma, pituitary-peripheral gradient at intrapetrosal sinus sampling, macroscopic and microscopic confirmation. During the study period, 53 consecutive patients with corticotroph microadenomas were operated on by enlarged adenomectomy. The population consisted of 49 women and four men, aged $39 \pm 13$ years (range 13-62 years). During the same period, five other patients with histologically proven small corticotroph microadenomas were treated by total hypophysectomy and four patients were treated by anticortisol therapy in the absence of radiological or peroperative visualization of a microadenoma.

\section{Hormone evaluation}

Nyctohemeral variations of plasma adrenocorticotrophic hormone (ACTH) and cortisol concentrations were measured every $4 \mathrm{~h}$ over $24 \mathrm{~h}$ in the preoperative period, 8 days after surgery, every 6 months for 18 months after surgery, and yearly thereafter. The plasma cortisol analysis was performed by a competition radioimmunoassay (Immunotech, Marseille, France), with normal values ranging from 200 to $700 \mathrm{nmol} / \mathrm{l}$ at $0800 \mathrm{~h}$ and 50 to $300 \mathrm{nmol} / \mathrm{l}$ at $2000 \mathrm{~h}$, and an assay sensivity of $20 \mathrm{nmol} / \mathrm{l}$. Plasma ACTH concentrations were measured by an immunoradiometric assay (Allegro kit, Nichols Institute, San Juan, Capistrano, CA, USA), with normal values ranging from 10 to $55 \mathrm{ng} / \mathrm{l}$ at $0800 \mathrm{~h}$ and 5 to $20 \mathrm{ng} / \mathrm{l}$ at $2000 \mathrm{~h}$, and an assay sensivity of $5 \mathrm{ng} / \mathrm{l}$. Urinary free cortisol (UFC) was measured after extraction, using a radioimmunoassay (Immunotech); normal values ranged from 80 to $300 \mathrm{nmol} / \mathrm{d}$.

To confirm the diagnosis of Cushing's disease, all patients underwent a low-dose dexamethasone suppression test $(0.5 \mathrm{mg}$ every $6 \mathrm{~h}$ during $48 \mathrm{~h}$, absence of suppression of the plasma cortisol to $50 \mathrm{nmol} / \mathrm{l}$ or less confirming Cushing's syndrome), followed by a highdose dexamethasone suppression test $(2 \mathrm{mg}$ every $6 \mathrm{~h}$ during $48 \mathrm{~h}$, suppression of plasma cortisol by $50 \%$ or more and UFC by $90 \%$ or more being consistent with Cushing's disease) $(9,12,22)$. Bilateral inferior petrosal sinus sampling for ACTH measurement before and after i.v. administration of $100 \mu \mathrm{g}$ corticotropin-releasing hormone $(\mathrm{CRH})$ was performed through a bilateral femoral vein approach in seven patients, to ascertain the pituitary origin of the ACTH hypersecretion. In all patients the central/peripheral gradient was $>2$ at baseline and $>3$ after CRH $(9,12,22)$.

Other pituitary functions were assessed by determination of basal hormone concentrations, by thyrotrophin-releasing hormone (TRH) and gonadotropinreleasing hormone $(\mathrm{GnRH})$ stimulation tests, and by measurements of urine volume and density.

No substitutive cortisol replacement therapy was given before the hormone evaluation performed 8 days after surgery. All subsequent cortisol/ACTH measurements in the patients receiving postoperative cortisol replacement therapy were performed $48 \mathrm{~h}$ after discontinuation of their cortisol treatment.

\section{Radiological investigations}

Fifty-one patients underwent pituitary MRI performed by the same neuroradiologist $(\mathrm{N} \mathrm{G})$. Images were obtained on a 1.0 T system (Magnetom SP 40; Siemens, Erlangen, Germany) using precontrast 3-mm thick contiguous coronal spin echo T1-weighted images (repetition time (TR) $450 \mathrm{~ms}$; echo time (TE) $22 \mathrm{~ms}$; three excitations), followed by postgadolinium threedimensional fourier transformed (FT) T1-weighted imaging using a fast, low-angle shot (flash) sequence (TR $40 \mathrm{~ms}$; TE $5 \mathrm{~ms}$; flip angle $40^{\circ}$ ) or turbo flash sequence (TR $10 \mathrm{~ms}$; TE $4 \mathrm{~ms}$; inversion time $200 \mathrm{~ms}$; flip angle $12^{\circ}$ ). The three-dimensional FT T1-weighted sequences provided 1-mm thick contiguous sections and reformatted images in any desired plane. The acquisition was performed in the sagittal plane to avoid aliasing phenomena. Reformatted images were obtained in the coronal plane, the oblique plane oriented along the pituitary stalk, and the axial plane oriented along the sellar floor. Additional 3-mm thick coronal T2-weighted images (turbo spin echo sequence; 
(a)

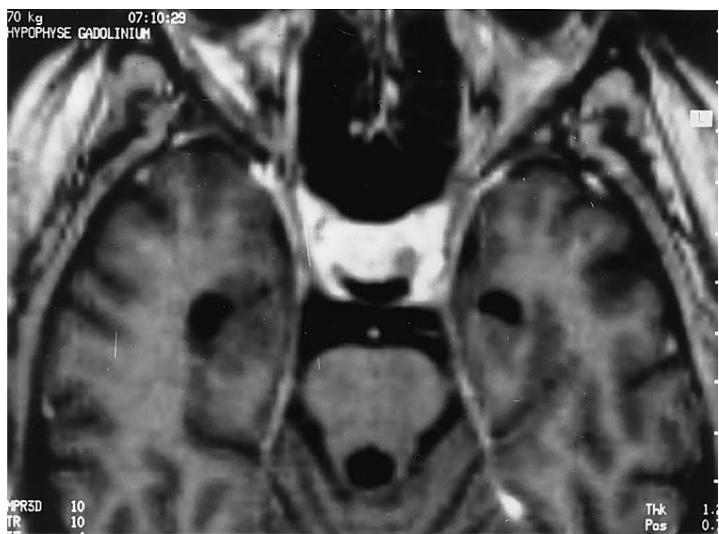

(b)

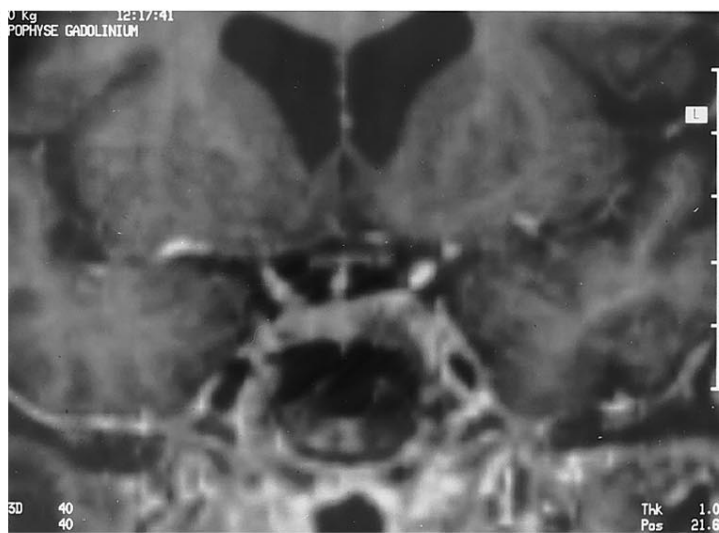

(c)

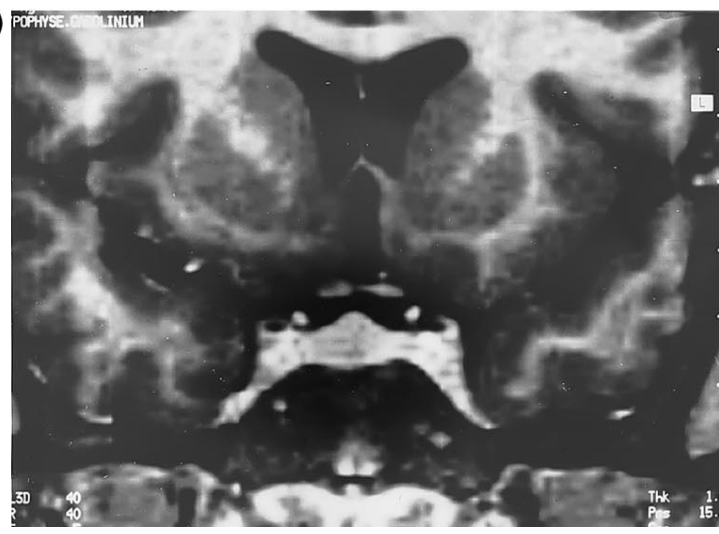

Figure $1 \mathrm{MRI}$ findings. (a) Postcontrast axial reformatted image: a left-sided microadenoma has low signal intensity within the enhancing gland. The lesion adheres to the cavernous sinus without spreading. (b) Postcontrast coronal reformatted image shows an adenoma extending through the left cavernous sinus as linear low signal intensities. (c) Postcontrast coronal reformatted image showing the microadenoma as focally heterogeneous with linear low signal intensities distributed through the right pituitary lobe.

TR $4300 \mathrm{~ms}$; TE $90 \mathrm{~ms}$; two excitations) have been performed since 1993. In each case, relationships of the lesion to both cavernous sinuses and the posterior lobe were carefully analyzed on a blinded basis by two independent investigators: a neuroradiologist (N G) and a neurosurgeon (H D). Each investigator was required to classify each adenoma either as 'invasive' or 'noninvasive', cases without definite evidence of extension beyond the anterior pituitary being classified into the latter group. Cavernous sinus or posterior lobe invasion was suspected on the basis of an uninterrupted extension of the adenomatous signal into the corresponding structure as illustrated in Fig. 1b. For various reasons, the two remaining patients were investigated by computed tomography only.

\section{Surgery}

All patients underwent surgery via the transsphenoidal approach, performed by the same neurosurgeon (F G) using a microscopic technique. An enlarged adenomectomy, removing the adenoma and the surrounding parenchyma, was performed as described previously (21). Before the adenoma was sought or penetrated, the two lateral wings were dissected, the surgeon keeping the approach outside the capsule. If the adenoma did not cross the midline, a section from above downwards was made, starting from the edge of the stalk, allowing removal, in one block, of the adenoma, the adjacent pituitary gland and its capsule. If the adenoma crossed the midline, it was removed by cutting a slice of normal pituitary gland about $1 \mathrm{~mm}$ thick and finally removing the lateral hypophyseal capsule in contact with the cavernous sinus. In each case, the neurosurgeon stated whether the removal was considered to be complete or partial on the basis of peroperative findings. Fragments labeled either 'tumor' or 'surrounding pituitary tissue' were placed into separate containers and sent to the pathologist.

\section{Histological methods}

All tumor specimens obtained at surgery were immediately fixed in Bouin-Holland and studied by the same pathologist (J T). When the tumor was not found at the first histological analysis $(n=15)$, the entire fragments were cut into serial sections. The presence of adenomatous tissue in surrounding pituitary samples was considered as indicative of microscopic tumor extension. The sections were stained by Herlant tetrachrome and PAS-Orange G and treated by the immunoperoxidase technique with streptavidin-biotin-complex. The following monoclonal $(\mathrm{m})$ and polyclonal $(\mathrm{p})$ antibodies were used at 1:200 to 1:4000 dilution: anti-p17-39ACTH (donated by M P Dubois, Nouzilly, France), antipßendorphin and anti-pßlipotropin (LPH) (donated by B Claustrat Lyon, France), anti-m human prolactin (hPRL) and anti-m $\alpha$-subunit (Immunotech), anti-p human growth hormone (donated by Dr Raiti, National Institute of Arthritis, Diabetes, Digestive and Kidney Diseases). 


\section{Surgical outcome}

The patients were classified into two groups according to the findings of their individual latest evaluation performed $2-10$ years after surgery $(3.2 \pm 1.8$ years). Patients were considered to be in remission $(n=38)$ on the basis of clinical cure and a $0800 \mathrm{~h}$ plasma cortisol concentration $<138 \mathrm{nmol} / \mathrm{l}$ at the day 8 evaluation (9), normalization of UFC and resumption of plasma ACTH and cortisol nyctohemeral variations at subsequent evaluations. Uncured patients $(n=15)$ included immediate failures $(n=10)$ characterized by $0800 \mathrm{~h}$ cortisol values $>138 \mathrm{nmol} / \mathrm{l}$ at the day 8 evaluation and increased cortisol concentrations at subsequent evaluations that proved to be partially suppressible during the low-dose dexamethasone test, and recurrences of hypercortisolism $(n=5)$ defined as recurrence of clinical and biochemical markers (including partial suppression at the low-dose dexamethasone test) of hypercortisolism 12-84 months (mean $37.2 \pm$ 27.6 months) after surgery in patients who had a morning cortisol concentration $<138 \mathrm{nmol} / \mathrm{l}$ at the early postoperative evaluation.

\section{Statistical analysis}

Quantitative variables are expressed as mean \pm s.E.M. and were analyzed wit the Mann-Whitney test (nonparametrical study). Qualitative variables were analyzed using Fisher's test. Statistical significance was achieved at a probability $(P)$ value less than 0.05 . All statistical tests were performed using the Stat Graph Plus statistical software package.

\section{Results}

\section{Preoperative clinical and biological status}

Age at diagnosis was not significantly different according to the outcome: $39 \pm 12$ years in patients in remission and $38 \pm 15$ years in those who were uncured. Preoperative UFC measurements averaged $1333 \pm 985 \mathrm{nmol} /$ day in the whole population and did not differ according to the outcome (1276 \pm $969 \mathrm{nmol} /$ day in cured and $1484 \pm 1049 \mathrm{nmol} /$ day in uncured patients), in keeping with $\mathrm{ACTH}$ and cortisol concentrations (data not shown). The other anterior pituitary functions were normal in all patients.

\section{Preoperative MRI findings}

Among the 51 patients examined by MRI, a focal lesion suggestive of an intrasellar adenoma was identified in 48 (sensitivity $=94 \%)$ in the left $(n=21)$ or right $(n=$ 24) side or in the median part $(n=3)$ of the gland (Fig. 1a), and signs of tumor extension to adjacent structures were present in 10 (Fig. 1b). Taking into account the whole population of 62 patients with Cushing's disease consecutively treated during the study period, MRI had a sensitivity of 48/60 (80\%) in identifying a microadenoma, as nine patients not treated by enlarged adenomectomy (because of a lack of visualization of their adenoma) were not included in the present report. In this series, the pituitary gland appeared heterogeneous after gadolinium enhancement without a tumoral image in three patients (Fig. 1c). The largest diameter of the adenoma ranged from 2 to $10 \mathrm{~mm}$, averaging $5.9 \pm 2.6 \mathrm{~mm}$, and was not significantly different in the two groups examined (Table 1). Signs of invasiveness were present in 10 of the individualized adenomas (21\%): cavernous invasion was documented by the presence of tumoral tissue extending into the cavernous sinus (Fig. 1b) in a total of eight patients and posterior lobe or stalk invasion was demonstrated in four. Notably, two patients presented with both types of invasion. Irrespective of the structure invaded, signs of tumor invasion were found to be significantly associated with an increased risk of poor outcome, as such signs were observed in $9 \%$ of patients in remission but in $54 \%$ of those who remained uncured (Table 1). MRI had very good specificity $(91 \%)$ for the prediction of surgery outcome (Table 2).

\section{Neurosurgical evaluation}

Macroscopic evidence of an intrasellar adenoma was found by the neurosurgeon in all the patients, enabling him to perform an enlarged adenomectomy. Taking into consideration all 58 patients operated on either by enlarged adenomectomy $(n=53)$ or by hypophysectomy

Table 1 Preoperative, peroperative and histological data in 53 patients with corticotroph microadenomas treated by enlarged adenomectomy.

\begin{tabular}{lcc}
\hline Parameter & $\begin{array}{c}\text { Patients in remission } \\
(n=38)\end{array}$ & $\begin{array}{c}\text { Uncured patients } \\
(n=15)\end{array}$ \\
\hline Largest diameter at MRI (mm) & $6.0 \pm 2.7$ & $5.6 \pm 2.5$ \\
Cavernous or posterior lobe invasion at MRI & $3 / 35$ & $7 / 13 \dagger$ \\
Cavernous or posterior lobe invasion (evaluation by neurosurgeon) & $4 / 35$ & $11 / 14 \ddagger$ \\
Histological visualization of the adenoma & $38 / 38$ & $13 / 15$ \\
Presence of adenomatous tissue in surrounding tissue samples & $5 / 26$ & $3 / 5 \S$ \\
\hline
\end{tabular}

Significantly different from patients in remission: $\uparrow P=0.02, \uparrow P=0.0001, \S P=0.03$. 
Table 2 Predictive value for surgical failure of the perioperative parameters of invasion, and of the immediate postoperative hormone evaluation.

\begin{tabular}{|c|c|c|c|c|}
\hline & $\begin{array}{l}\text { Sensitivity } \\
(\%)\end{array}$ & $\begin{array}{l}\text { Specificity } \\
(\%)\end{array}$ & $\begin{array}{c}\text { Positive } \\
\text { predictive value } \\
(\%)\end{array}$ & $\begin{array}{c}\text { Negative } \\
\text { predictive value } \\
(\%)\end{array}$ \\
\hline Cavernous or posterior lobe invasion at MRI & 54 & 91 & 70 & 84 \\
\hline $\begin{array}{l}\text { Cavernous or posterior lobe invasion at peroperative evaluation } \\
\text { by the neurosurgeon }\end{array}$ & 79 & 89 & 73 & 91 \\
\hline Presence of adenomatous tissue in surrounding tissue samples & 60 & 81 & 38 & 91 \\
\hline
\end{tabular}

Sensitivity was calculated as the ratio of the number of true positives to true positives plus false negatives, and specificity as the ratio of the number of true negatives to true negatives plus false positives. Positive predictive value was calculated as the ratio of the number of true positives to true plus false positives, and negative predictive value as the ratio of the number of true negatives to true plus false negatives.

$(n=5)$ during the study period, an adenoma was identified by the surgeon in $91 \%$. In 15 of those undergoing enlarged adenomectomies, the limits between the tumor and the surrounding normal pituitary were not clear. This macroscopic appearance of local invasiveness was a significantly discriminant parameter of the outcome, with good sensitivity (79\%) and specificity (89\%) (Tables 1 and 2).

\section{Histological findings}

An adenoma was identified by histological analysis in 51 of the 53 patients $(96 \%)$. The two in whom no adenoma was found by the pathologist were classified as early failures and may be explained either by erroneous identification of the adenoma by the neurosurgeon or by aspiration of adenomatous tissue during surgical procedure. By immunohistochemistry, with the exception of two plurihormonal ACTH and PRL adenomas, all tumors were monohormonal corticotroph adenomas. The tumoral cells were positive for antibodies against pro-opiomelanocortin-derived peptides (anti-ACTH, anti- $\beta$ endorphin and anti$\beta \mathrm{LPH}$ ). Fragments of the non-tumoral pituitary (samples labeled as surrounding pituitary tissue) were studied in 31 patients. Although, in all of them, no capsule was observed (Fig. 2a), 74\% of the tumors were well limited and no adenomatous tissue was present in the surrounding tissue samples from these patients (Fig. 2b). However, in eight, the limits were irregular and tumor cells invaded the juxtatumoral pituitary (Fig. 2c). This feature was significantly correlated with a poor outcome (Table 1), with a specificity of $81 \%$ (Table 2). In the juxtatumoral pituitary, numerous PRL cells were found in three patients. The corticotroph cells were either normal or displayed Crooke's changes in 28 of the 31 patients. Their number varied from rare to numerous, but according to the mapping of human corticotroph cells (23), no ACTH cell hyperplasia was found, whether or not an adenoma was present.

\section{Postoperative results}

Irrespective of the eventual hormonal outcome, ACTH or cortisol circadian variations at day 8 after surgery were absent or moderate, and no statistically significant difference was found between outcome groups, leading us to compare groups on the basis of the 08:00 h cortisol or ACTH values. Patients in remission and those who remained uncured as defined in the Methods section had significantly $(P=0.0001)$ different morning plasma cortisol concentrations on day $8(44 \pm 43 \mathrm{nmol} / \mathrm{l}$ and $334 \pm 421 \mathrm{nmol} / \mathrm{l}$, respectively), but this value was not statistically different $(P=0.8)$ between patients in longterm remission and those who later proved to have recurrent disease $(44 \pm 43 \mathrm{nmol} / \mathrm{l}$ and $54 \pm 28 \mathrm{nmol} / \mathrm{l}$, respectively). Similarly, morning ACTH $(11 \pm 7 \mathrm{ng} / \mathrm{l}$ and $36 \pm 39 \mathrm{ng} / \mathrm{l}$, respectively) and UFC $(24 \pm 21$ $\mathrm{nmol} /$ day and $365 \pm 743 \mathrm{nmol} /$ day, respectively) were significantly different $(P=0.03$ and $P=0.0001$, respectively) between patients in remission and uncured patients. Comparison of morning ACTH $(11 \pm 7 \mathrm{ng} / \mathrm{l}$ and $12 \pm 7 \mathrm{ng} / \mathrm{l}$, respectively) and UFC (24 \pm $21 \mathrm{nmol} /$ day and $36 \pm 41 \mathrm{nmol} /$ day, respectively) at day 8 showed no significant difference $(P=0.9$ and $P=$ 0.1 , respectively) between those in long-term remission and those with later recurrent disease. The duration of postoperative cortisol replacement therapy was similar in all outcome groups: $17 \pm 12$ months (range 3-72 months) in patients in remission and $22 \pm 10$ months (range 12-36 months) in uncured patients. A transient diabetes insipidus was observed in the immediate postoperative period in nine patients who had normal posterior pituitary function when re-evaluated without treatment 3 months later. At the month 6 visit, urinary volumes and densities were normal in the entire population. Baseline PRL, free thyroxine, TSH, testosterone and estradiol were normal in all patients, as were TSH and gonadotropin responses to TRH or GnRH tests, respectively.

\section{Discussion}

Immediate control of hypercortisolism was achieved in $81 \%$ of our patients, thanks to a surgical strategy aimed at removing the adenoma whenever possible, using enlarged adenomectomy. However, 9\% of our population experienced a late recurrence of disease. 

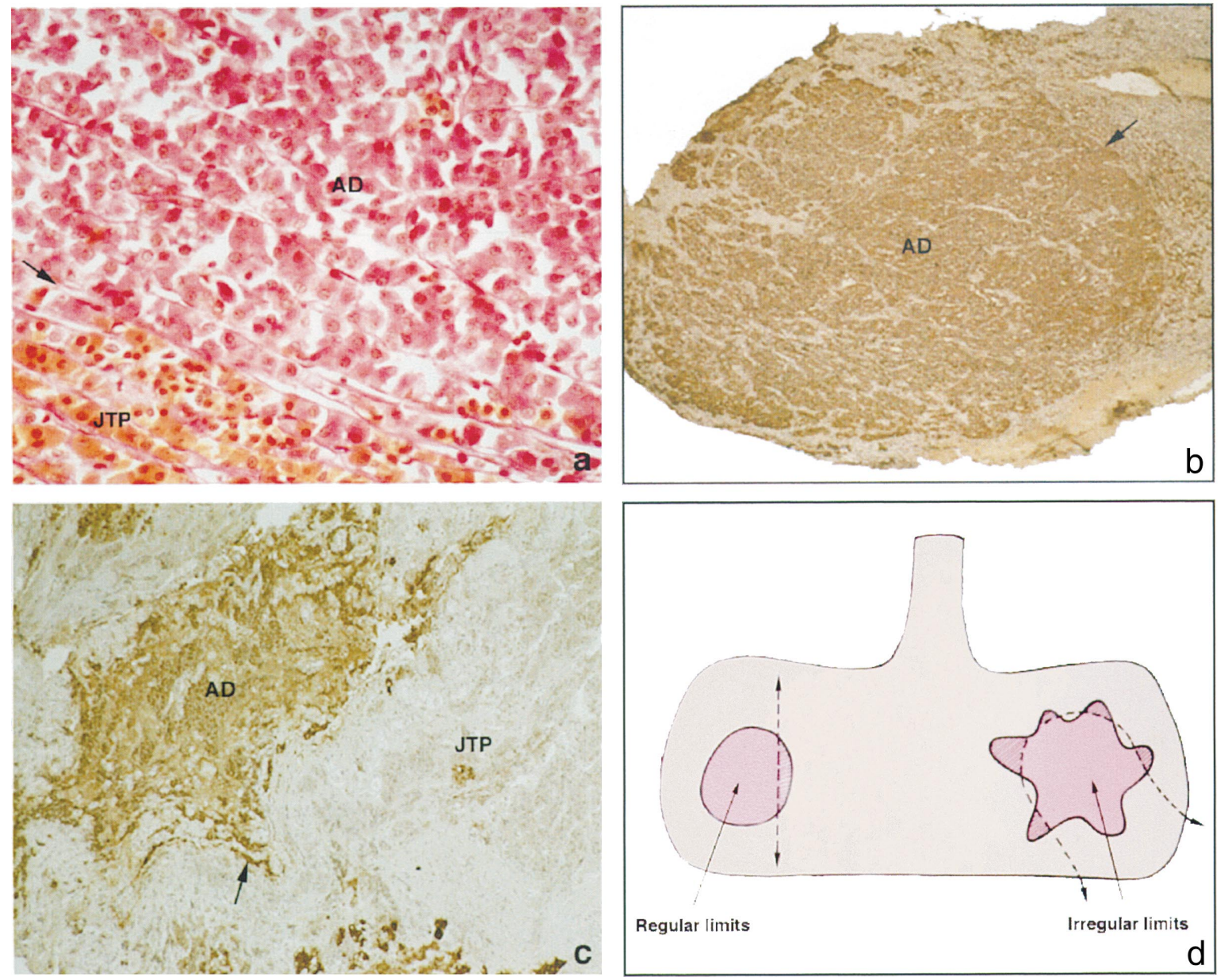

Figure 2 Histology of the corticotroph adenoma and the juxtatumoral pituitary. (a) Limits between a corticotroph adenoma (AD) and the juxtatumoral pituitary (JTP). Notice the absence of capsule (arrow) and the difference of cellular arrangement: diffuse in the tumor; in cords in the juxtatumoral pituitary. All the tumoral cells are PAS positive. The orangeophilic cells are normal somatotrophs (PAS-Orange G, $\times 1000)$. (b) This corticotroph adenoma (AD), positive for anti-ACTH antibodies, is round with regular limits $($ arrow) $(\times 120)$. (c) This small adenoma (AD), less than $2 \mathrm{~mm}$ in diameter, has irregular limits, with cell cords invading (arrow) the juxtatumoral pituitary (JTP) $(\times 250)$. Immunoperoxidase technique, with anti-17-39-ACTH at a dilution of 1:4000. (d) Diagram showing how tumoral cells may be left behind if a selective adenomectomy is performed.

As previously described (24), this study used threedimensional FT MRI to achieve a more accurate determination of local invasiveness and, in particular, spread into the cavernous sinus and the neurohypophysis. Moreover, the peroperative macroscopic evaluation of the extent of tissue requiring removal by the neurosurgeon was closely related to the pathological diagnosis, including an immunocytochemical analysis of the juxtatumoral pituitary. These features, together with more commonly studied parameters were analyzed and confirmed that the frequency of recurrences in this disease is most probably linked to the local invasiveness of corticotroph microadenomas. Our series included 51 patients with histologically proven corticotroph microadenoma and two patients with Cushing's disease confirmed by standard endocrine findings and bilateral intrapetrosal sinus sampling. These patients were further analyzed in terms of prognostic factors to assess the results of transsphenoidal enlarged adenomectomy. It was noteworthy that, despite such an enlarged tumor removal, all pituitary functions - with the exception of the hypothalamo-pituitary-adrenal axis - were found to be normal 3 months after surgery in all patients. The minimum duration of follow-up selected in this study (24 months) does not permit exclusion of the possibility of later recurrences in some of the patients evaluated. However, according to published series $(1,25,26)$ most recurrences occur within 2 years after surgery, and our mean duration of followup was $38 \pm 22$ months (range 24-120 months).

In this population, among hypo- or eucortisolic patients, early postoperative morning cortisol concentrations from patients in long-term remission were not 
significantly different from those of patients who later experienced recurrence of hypercortisolism, in contrast with other data reported in the literature $(1,16,18$, 25, 27-29). Several dynamic tests have been used in the assessment of the surgical outcome of Cushing's disease. Patients with low serum cortisol concentrations that suppress with low-dose dexamethasone test may generally be cured $(16,17)$. In contrast, a restoration of cortisol suppression has been described after incomplete adenomectomy (19). Moreover, in a few cases, a partial cortisol suppression can exist before surgery for Cushing's disease (16). Discrepant results were also described with $\mathrm{CRH}$ test as a predictor for surgical outcome $(1,12,15,20)$. Recently, desmopressin (ddAVP), a synthetic vasopressin analogue acting on pituitary $\mathrm{V} 3$ (or $\mathrm{V} 1 \mathrm{~b}$ ) receptors, which mediates ACTH and cortisol secretion in patients with corticotroph adenomas, was used as a test for the diagnosis of Cushing's disease (22, 30). However, preliminary postoperative results showed the persistence of ACTH hyperresponsiveness to ddAVP in patients with cured Cushing's disease. Overall, no test has proved to be completely reliable in the etiological diagnosis of ACTHdependent hypercortisolism or in the assessment of cure $(17,22)$.

In our series of patients, tumor visualization by MRI $(94 \%)$, by the surgeon $(100 \%)$ or by histological examination $(96 \%)$ was not correlated with the outcome. This finding was expected because, during the study period, nine patients with corticotroph microadenomas were treated by either total hypophysectomy or anticortisolic therapy because no adenoma had been visualized, and were thus excluded from the present series that analyzed potential predictive criteria for cure after enlarged adenomectomy. Three-dimensional MRI appeared to be very helpful in the management of our patients. Indeed, it allowed visualization of an intrasellar adenoma in $80 \%$ of all patients, and in $94 \%$ of those treated by enlarged adenomectomy, with exact localization of the tumor in all the positive cases. In previously published series $(1,6,31)$, a greater risk of immediate failure seemed to be associated with the absence of visualization of the tumor. Similarly, absence of visualization of the tumor by the surgeon or the pathologist seemed to be associated with a greater risk of surgical failure $(1,7,12,31)$. We paid particular attention to the local invasiveness of corticotroph microadenomas, by means of neuroradiology, surgery and histology. Previous studies had been unable to link the neuroradiological signs of invasiveness to the surgical outcome $(6,12)$. In our series, MRI revealed invasion of the surrounding structures in 10 patients. This parameter was significantly linked to an increased risk of poor outcome and was characterized by the best specificity score (91\%). Combining both kinds of predictive values (positive and negative), signs of tumor invasiveness at MRI can be considered a reliable risk factor of surgical failure. Interestingly, macroscopic evaluation of local invasiveness, an unfrequently analyzed parameter in published series, was also indicative of the surgical result in our patients (sensitivity 79\%; specificity 89\%). Although such an assessment may have been influenced by the surgeon's awareness of radiological signs of tumor extension, it was based on peroperative macroscopic observation. The histological analysis of the juxtatumoral pituitary performed on a blind basis showed that $26 \%$ of corticotroph microadenomas had irregular limits. This locoregional spreading, observed in our series in $60 \%$ of the recurrent tumors and in $19 \%$ of long-term remissions, is not related to malignancy or particular aggressiveness. The recurrence may be explained by tumor regrowth from tumoral cells lining the adjacent normal pituitary preserved by the surgeon, especially when tumor limits had not been clearly demarcated (Fig. 2d). Moreover, extension of tumoral tissue into the peritumoral rim in patients in remission suggests that removal of macroscopically normal pituitary tissue around the visible lesion might have been beneficial in these patients. Similar observations have been made in other types of pituitary adenomas (21). Unlike other authors (7), we found no evidence of corticotroph hyperplasia in the specimens analyzed. We thus believe that early surgical failure is not related to corticotroph hyperplasia, but to the fact that the microadenoma has been only partially removed by the surgeon.

The findings of the present study underline the high frequency of both macroscopic and microscopic invasion in corticotroph microadenomas. On a total of 10 parameters analyzed, signs of local tumor invasiveness were found to be good predictors of long-term outcome of patients with Cushing's disease treated by transsphenoidal adenomectomy, at three-dimensional FT MRI examination, during the surgical procedure, or at histological analysis. Tumor extension thus appeared as the principal risk factor of these microadenomas and justified performance of enlarged adenomectomy. This surgical strategy should decrease the risk of immediate failure or of late recurrence. On an individual basis, however, a long-term clinical and biological follow-up is warranted in all patients, to ascertain a definitive cure.

\section{Acknowledgements}

The authors wish to thank M P Guigard for excellent technical assistance and $\mathrm{C}$ Taverna for the preparation of the manuscript.

\section{References}

1 Bochicchio D, Losa M \& Buchfelder M. Factors influencing the immediate and late outcome of Cushing's disease treated by transsphenoidal surgery: a retrospective study by the European Cushing's disease survey study group. Journal of Clinical Endocrinology and Metabolism $1995 \mathbf{8 0} 3114-3120$. 
2 Extabe J \& Vazquez JA. Morbidity and mortality in Cushing's disease: an epidemiologic approach. Clinical Endocrinology 1994 40 479-484.

3 Hardy J. Transsphenoidal microsurgery of the normal and pathological pituitary. Clinical Neurosurgery 196916 185-217.

4 Boggan JE, Tyrrell JB \& Wilson CB. Transsphenoidal microsurgical management of Cushing's disease. Report of 100 cases. Journal of Neurosurgery $1983 \mathbf{5 9} 195-200$.

5 Tyrrell JB, Brooks RM, Fitzgerald PA, Cofoid PB, Forsham PH \& Wilson CB. Cushing's disease selective transsphenoidal resection of pituitary microadenomas. New England Journal of Medicine $1978298753-758$.

6 Barrou Z, Abecassis JP, Guilhaume B, Thomopoulos P, Bertagna X, Derome $\mathrm{P}$ et al. Magnetic resonance imaging: prediction of surgical outcome. Presse Médicale (Paris) 199726 7-11.

7 Guilhaume B, Bertagna X, Thomsen M, Bricaire C, Vila-Porcile E, Olivier L et al. Transsphenoidal pituitary surgery for the treatment of Cushing's disease: results in 64 patients and long term follow-up studies. Journal of Clinical Endocrinology and Metabolism 198866 1056-1064.

8 Nakane T, Kuwayama A, Watanabe M, Takahashi T, Kato T, Ichihara $\mathrm{K}$ et al. Long term results of transsphenoidal adenomectomy in patients with Cushing's disease. Neurosurgery 1987 $21218-222$.

9 Orth DN. Medical progress: Cushing's syndrome. New England Journal of Medicine 1995332791.

10 Robert F \& Hardy J. Cushing's disease: a correlation of radiological, surgical and pathological finding with therapeutic results. Pathology, Research and Practice 1991187 617-621.

11 Tagliaferri M, Berselli ME \& Loli P. Transsphenoidal microsurgery for Cushing's disease. Acta Endocrinologica 1986113 5-11.

12 Invitti C, Pecori Giraldi F, de Martin M \& Cavagnini F. Diagnosis and management of Cushing's syndrome: results of an Italian multicentre study. Journal of Clinical Endocrinology and Metabolism 199984 440-448.

13 Burke CW, Adams CB, Esiri MM, Morris C \& Bevan JS. Transsphenoidal surgery for Cushing's disease: does what is removed determine the endocrine outcome? Clinical Endocrinology 199033 525-537.

14 Lamberts SW, Klijn JG \& de Jong FH. The definition of true recurrence of pituitary-dependent Cushing's syndrome after transsphenoidal operation. Clinical Endocrinology $1987 \quad 26$ 707-712.

15 Nishizawa S, Oki Y, Ohta S, Yokota N, Yokoyama T \& Uemura K. What can predict postoperative 'endocrinological cure' in Cushing's disease? Neurosurgery 199945 239-244.

16 McCance DR, Gordon DS, Fannin TF, Hadden DR, Kennedy L, Sheridan B et al. Assessment of endocrine function after transsphenoidal surgery for Cushing's disease. Clinical Endocrinology $19933879-86$.

17 McCance DR, Besser M \& Atkinson AB. Assessment of cure after transsphenoidal surgery for Cushing's disease. Clinical Endocrinology $1996 \mathbf{4 4} 1-6$.

18 Trainer PJ, Lawrie HS, Verhelst J, Howlett TA, Lowe DG, Grossman $\mathrm{AB}$ et al. Transsphenoidal resection in Cushing's disease: undetectable serum cortisol as the definition of successful treatment. Clinical Endocrinology 199338 73-78.
19 Jeffcoate WJ, Qawncey S \& Selby C. Restauration of dexamethasone suppression by incomplete adenomectomy in Cushing's disease. Clinical Endocrinology 198523 193-199.

20 Schrell U, Fahlbusch R, Buchfelder M, Riedl S, Stalla GK \& Muller OA. Corticotropin-releasing hormone stimulation test before and after transsphenoidal selective microadenomectomy in 30 patients with Cushing's disease. Journal of Clinical Endocrinology and Metabolism 198764 1150-1159.

21 Grisoli F, Brue T, Graziani N, Costa R, Trouillas J, Begou D et al. Enlarged adenomectomy for enclosed prolactinomas: a preliminary study of 26 cases. Acta Neurochirurgica (Wien) 1990103 92-98.

22 Newell-Price J, Trainer P, Besser M \& Grossman A. The diagnosis and differential diagnosis of Cushing's syndrome and pseudoCushing's states. Endocrine Reviews 199819 647-672.

23 Trouillas J, Guigard MP, Souchier C \& Girod C. Mapping of corticotropic cells in the normal human pituitary. Journal of Histochemistry and Cytochemistry $1996 \mathbf{8 2} 473-479$.

24 Girard N, Mugnier M, Dufour H, Trouillas J, Brue T, Raybaud C et al. Magnetic resonance imaging findings in Cushing disease. International Journal of Neuroradiology 19973 319-326.

25 Devoe DJ, Miller WL, Conte FA, Kaplan SL, Grumbach MM, Rosenthal SM et al. Long-term outcome in children and adolescents after transsphenoidal surgery for Cushing's disease. Journal of Clinical Endocrinology and Metabolism 1997823196 3202.

26 Leinung MC, Kane LA, Scheithauer BW, Carpenter PC, Laws ER Jr \& Zimmerman D. Long term follow-up of transsphenoida surgery for the treatment of Cushing's disease in childhood Journal of Clinical Endocrinology and Metabolism $1995 \mathbf{8 0} 2475$ 2479.

27 Toms GC, McCarthy MI, Niven MJ, Orteu CH, King TT \& Monson JP. Predicting relapse after transsphenoidal surgery for Cushing's disease. Journal of Clinical Endocrinology and Metabolism $199376291-294$.

28 Pieters GF, Hermus AR, Meijer E, Smals AG \& Kloppenborg PW. Predictive factors for initial cure and relapse rate after pituitary surgery for Cushing's disease. Journal of Clinical Endocrinology and Metabolism $1989691122-1126$.

29 Mampalam TJ, Tyrrell JB \& Wilson CB. Transsphenoidal microsurgery for Cushing disease. A report of 216 cases. Annals of Internal Medicine $1988 \mathbf{1 0 9}$ 487-493.

30 Newell-Price J, Perry L, Medbak S, Monson J, Savage M, Besser $\mathrm{M}$ et al. A combined test using desmopressin and corticotropin-releasing hormone in the differential diagnosis of Cushing's syndrome. Journal of Clinical Endocrinology and Metabolism 199782 176-181.

31 Bakiri F, Tatai S, Aouali R, Semrouni M, Derome P, Chitour F et al. Treatment of Cushing's disease by transsphenoidal, pituitary microsurgery: prognosis factors and long-term follow-up. Journal of Endocrinological Investigation 199619 572-580.

Received 29 March 2000

Accepted 23 August 2000 